\title{
Amebas testáceas (Arcellinida e Euglyphida) em dois biótopos de um corpo aquático temporário contaminado por dejetos orgânicos: novas ocorrências para o estado da Bahia
}

Testate amoebae (Arcellinida and Euglyphida) in two biotopes of a temporary aquatic body contaminated by organic waste: new records to Bahia state

\author{
L. J. Gomes da Silva ${ }^{1}$; M. B. Silva ${ }^{1 *}$; R. E. Fraga ${ }^{1}$; M. S. Anjos ${ }^{1}$; C. V. S. Rocha ${ }^{1}$; \\ S. P. Santos 2 ; M. A. Rocha ${ }^{3}$ \\ ${ }^{1}$ Laboratório de Zoologia, Instituto Multidisciplinar em Saúde, Universidade Federal da Bahia, Campus Anísio \\ Teixeira, 45029-094, Vitória da Conquista-BA, Brasil \\ ${ }^{2}$ Universidade Estadual de Santa Cruz, 45065-010, Vitória da Conquista- BA, Brasil. \\ ${ }^{3}$ LABIMAR: Laboratório de Invertebrados Marinhos e fauna associada, Instituto de Biologia, Universidade Federal \\ da Bahia, Campus Ondina, 40170-115, Salvador-BA, Brasil \\ *biolmarcioborba@gmail.com
}

(Recebido em 21 de março de 2020; aceito em 12 de junho de 2020)

\begin{abstract}
Lagoas temporárias são ambientes efêmeros pouco estudados. O objetivo deste trabalho foi inventariar a comunidade de amebas testáceas encontradas em dois biótopos (plâncton e perifíton) de um corpo aquático temporário contaminado por dejetos orgânicos. As coletas foram realizadas entre junho e setembro de 2018 na Fazenda Periperi, Vitória da Conquista, Bahia. Foram coletadas 51 amostras planctônicas e 12 perifíticas. As análises físico-químicas foram realizadas in situ e as bacteriológicas em laboratório através do kit Colilert ${ }^{\circledR}$. A água deste ambiente é alcalina, com elevados valores de temperatura, sólidos totais dissolvidos e condutividade elétrica. Apresentou baixos teores de oxigênio dissolvido e transparência, refletindo a elevada biomassa fitoplanctônica presente. Os valores de coliformes totais e termotolerantes demonstraram contaminação fecal na água. Foram registrados 32 taxa de amebas testáceas distribuídos em 11 gêneros e oito famílias. A maior riqueza foi registrada no plâncton (23 taxa), seguido de Pistia sp. e Salvinia sp. (18 taxa cada). As famílias encontradas no plâncton foram Difflugiidae, Arcellidae, Centropyxidae, Cryptodifflugiidae, Netzeliidae e Trigonopyxidae, e nas macrófitas foram Difflugiidae, Lesquereusiidae, Netzeliidae e Euglyphidae. Seis espécies constituem primeiras ocorrências para o estado da Bahia: Arcella costata, Ciclopyxis arcelloides, Difflugia dragana, D. gigantea, D. kabylica e D. helvetica. Com o desaparecimento das macrófitas, houve intercambio espacial das espécies Centropyxis hirsuta, D. kabylica e Pentagonia maroccana para o plâncton, evidenciando a plasticidade destes organismos em ocupar ambientes eutrofizados, instáveis e sazonais, tolerando contaminação fecal.

Palavras-chave: Lagoa temporária, tecamebas, nordeste.
\end{abstract}

Temporary ponds are ephemeral environments little studied. The objective of this work was to inventory the community of testate amoebae found in two biotopes (plankton and periphyton) of a temporary aquatic body contaminated by organic waste. The collections were carried out between June and September 2018 at Fazenda Periperi, Vitória da Conquista, Bahia. 51 planktonic and 12 periphytics samples were collected. Physical-chemical analyzes were performed in situ and bacteriological analyzes in the laboratory using the Colilert ${ }^{\circledR}$ kit. The water in this environment is alkaline, with high temperature values, total dissolved solids and electrical conductivity. It had low levels of dissolved oxygen and transparency, reflecting the high phytoplankton biomass present. The values of total and thermotolerant coliforms demonstrated fecal contamination in the water. There were 32 taxa of testate amoebae distributed in 11 genera and eight families. The greatest richness was registered in plankton (23 taxa), followed by Pistia sp. and Salvinia sp. (18 taxa each). The families found in the plankton were Difflugiidae, Arcellidae, Centropyxidae, Cryptodifflugiidae, Netzeliidae and Trigonopyxidae, and the macrophytes were Difflugiidae, Lesquereusiidae, Netzeliidae and Euglyphidae. Six species are the first occurrences for the state of Bahia: Arcella costata, Ciclopyxis arcelloides, Difflugia dragana, D. gigantea, D. kabylica and D. helvetica. With the disappearance of macrophytes, there was a spatial exchange of Centropyxis hirsuta, D. kabylica and Pentagonia maroccana species for plankton, showing the plasticity of these organisms in occupying eutrophic, unstable and seasonal environments, tolerating fecal contamination.

Keywords: Temporary pond, testate amoebae, northeast. 


\section{INTRODUÇÃO}

Amebas testáceas são organismos eucariontes, unicelulares de vida livre, heterotróficos, que ocorrem em ambientes terrestres úmidos (solo, musgos) e aquáticos. Possuem carapaças (tecas) rígidas que proporcionam elevado aspecto bioindicador ambiental $[1,2,3]$ e protegem seu protoplasma [4]. Através da sua abertura esses organismos emitem os pseudópodes que auxiliam na locomoção e alimentação (matéria orgânica morta, bactérias, diatomáceas, outros protozoários e nematoides) [1,5]. Vale ressaltar que a morfologia da carapaça é altamente variável e dependente das condições ambientais [2,3].

Além da sensibilidade frente as mudanças ambientais, os organismos planctônicos podem responder rapidamente aos mais diversos tipos de impactos [6]. O crescimento populacional em torno dos corpos hídricos tem provocado distúrbios nesses ecossistemas, processo de eutrofização, causada pela alta concentração de nutrientes (principalmente nitrogênio e fósforo) e matéria orgânica [7]. Algumas espécies de amebas testáceas possuem elevada resistência à metais pesados ou contaminação bacteriana [8]. Outras podem regular a densidade fitoplanctônica em lagos eutróficos [9] constituindo mais de $30 \%$ da biomassa microbiana nestes ambientes [10, 11] demonstrando assim a sua plasticidade.

Quanto a sua ocorrência, autores relatam [12] que embora muitos estudos apontem que as amebas testáceas ocorram preferencialmente associadas a macrófitas aquáticas, a sua ocorrência no compartimento planctônico é frequente, havendo nítidos padrões de ocorrência e abundância relativa das amebas testáceas entre os diferentes biótopos investigados por eles na bacia do rio Paraná.

Apesar de sua elevada importância para a estrutura e funcionamento de ecossistemas aquáticos, os estudos deste grupo são incipientes. A maioria das pesquisas sobre a diversidade de amebas testáceas no Brasil foi realizada nas regiões Centro-Oeste, Sul e Sudeste [13-27]. Na região Nordeste, apesar de possuir uma abundância em corpos aquáticos, existem poucos registros destes organismos, devido à carência de inventários taxonômicos sobre amebas testáceas face à escassez de pesquisadores especializados na taxonomia do grupo [8].

O estado da Bahia é a quinta região mais extensa do território brasileiro (cerca de 564.732 .450 $\mathrm{km}^{2}$ ), entretanto, considerando a quantidade de corpos aquáticos no estado, poucos estudos sobre a biodiversidade de amebas testáceas são investigados.

A primeira pesquisa que incluiu a fauna de protozoários no estado da Bahia foi publicada em 1916 [28], onde estudou-se as comunidades de amebas testáceas na localidade de Remanso no bioma Caatinga, registrando a ocorrência de Centropyxis aculeata Ehrenberg, 1988 e Trinema enchelys Ehrenberg, 1938. Posteriormente, estudos sobre as comunidades de plâncton no Rio São Francisco, norte da Bahia, registraram as espécies: Arcella vulgaris Ehrenberg, 1830, Arcella dentata Ehrenberg, 1830 e Centropyxis aculeata Ehrenberg, 1830 para a estação de Itaparica [29].

Em 2009, pesquisa realizada no Rio Cachoeira, Bahia, Brasil, registrou 115 taxa de amebas testáceas [30], sendo destes 111 considerados novos registros para o estado e 84 para o Nordeste, elevando assim o número de espécies conhecidas de 54 espécies para o total de 138 taxa no Nordeste brasileiro. Em 2012, um levantamento de amebas testáceas em sedimentos na Baía do Iguape, Baía de Todos os Santos [31], inventariou 13 espécies nesta região, dos quais 06 constituem novas adições ao procta de amebas testáceas para o estado (Difflugia protaeiformis Lamarck, 1816; Nebela longicollis Penard, 1890, Phryganella nidulus Penard, 1902, Diplochlamys leidyi Greeff, 1888; Cochliopodium pellucidum Hertwig \& Lesser, 1874; 1972 e Penardochlamys arcelloides Penard, 1904).

Recentemente, um inventário da comunidade zooplanctônica realizada no reservatório natural em Glória- Bahia [32] identificou 38 taxa de organismos zooplanctônicos, dos quais três pertenciam ao grupo das amebas testáceas (Arcella sp. Ehrenberg, 1832, Centropyxis aculeata Ehrenberg, 1838 e Difflugia limnetica Levander, 1900), sendo esta última espécie registrada pela primeira vez no estado. Em síntese, o procta das amebas testáceas para o Estado da Bahia atualmente é constituído por 123 taxa.

Em regiões semiáridas, as lagoas temporárias são comuns e marcadas principalmente pelas elevadas temperaturas, evaporação e regime pluviométrico irregular. Estes ambientes podem ser caracterizados por episódios constantes de seca e ciclos de inundação [33] abrigando assim 
comunidades de organismos fisiologicamente adaptados a estas condições ambientais, capazes de colonizar, permanecer e reproduzir-se. Estudos das comunidades zooplanctônicas nestes ambientes são também escassos, restringindo-se aos grupos de Rotifera, Cladocera e Copepoda $[34,35]$. Assim as comunidades de amebas testáceas nestes ambientes efêmeros são subestimadas.

O presente trabalho, portanto, teve como objetivo inventariar a comunidade de amebas testáceas em dois biótopos (plâncton e perifíton) de um corpo aquático temporário e contaminado por dejetos orgânicos, fezes de animais, no nordeste do país. Especificamente, pretende-se: (i) ampliar o conhecimento sobre a biodiversidade destes organismos no estado da Bahia; (ii) fornecer informações sobre a sua ocorrência em um ambiente temporário e contaminado por dejetos orgânicos (eutrofizado) e (iii) verificar a distribuição das espécies entre dois biótopos (plâncton e perifíton).

\section{MATERIAL E MÉTODOS}

\section{1 Área de estudo}

A Fazenda Periperi $\left(14^{\circ} 48.178^{\prime} \mathrm{S} ; 40^{\circ} 48.376^{\prime} \mathrm{O}\right)$ localiza-se no centro industrial de Vitória da Conquista, sudoeste da Bahia, semiárido baiano (Figura 1). A fazenda apresenta vegetação arbustiva distribuída de forma esparsa no ambiente, com espécimes da flora típicos do bioma Caatinga. A área de estudo foi selecionada por ser um ambiente comum em regiões semiáridas, onde as pessoas aproveitam escavações no solo para acúmulo de água de chuva e dessedentação de animais.

O corpo aquático em estudo, localizado na fazenda Periperi, é caracterizado como ambiente temporário (Figura 1), possuindo cerca de $55 \mathrm{~m}$ de comprimento, $35 \mathrm{~m}$ de largura e aproximadamente $60 \mathrm{~cm}$ de profundidade. Este ambiente foi formado pela escavação do solo para extração de argila utilizada nas olarias da região, resultando na depressão do solo e acúmulo de água. A lagoa possui um pequeno estande de macrófitas aquáticas dos gêneros Pistia sp. e Salvinia sp. Entretanto, ao longo do período amostral, o local não recebeu chuvas e, com isso, houve significativa redução do volume de água (Figura 2), o que foi perceptível durante os meses e acarretou na diminuição de réplicas na amostragem final.

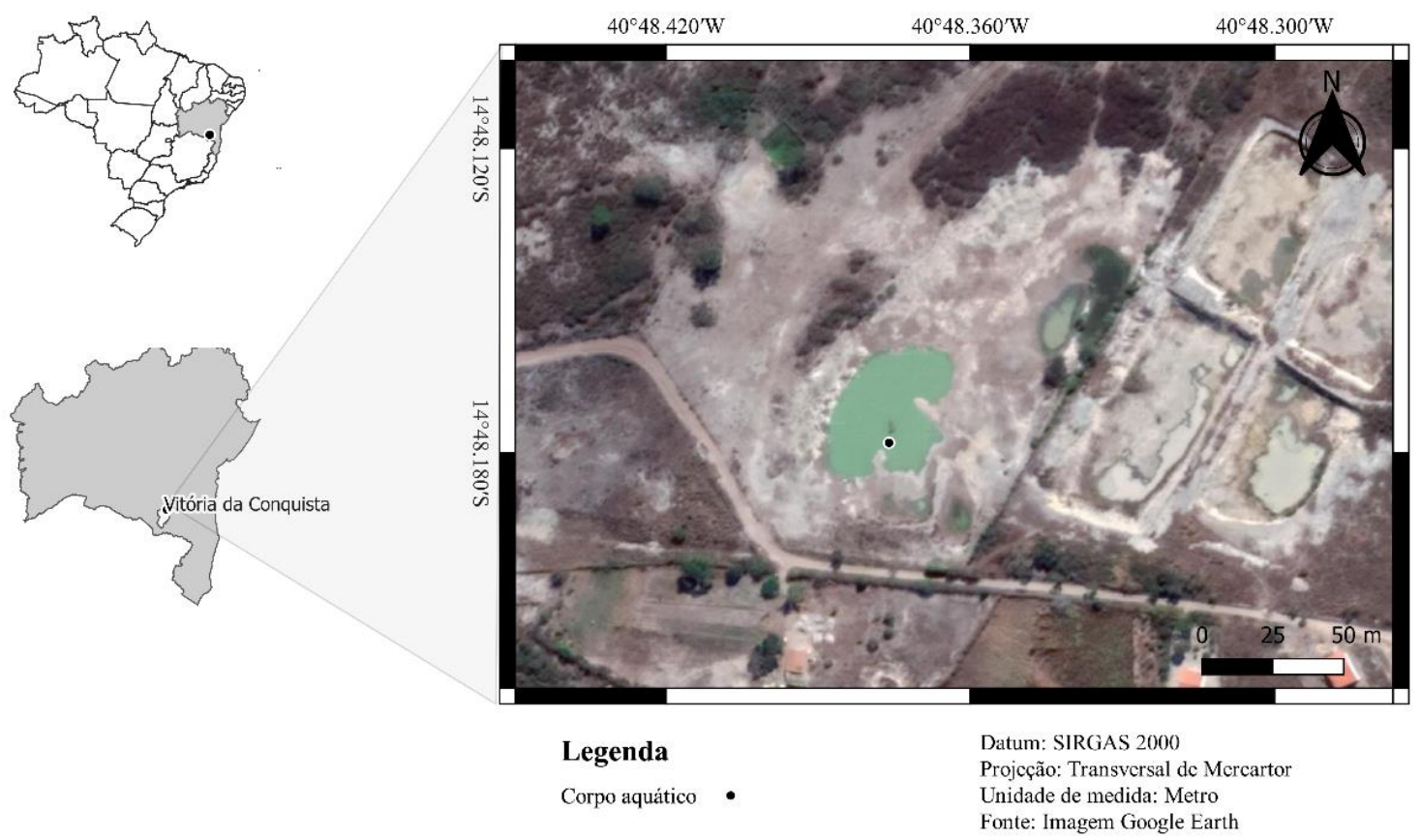

Figura 1: Localização do corpo aquático amostrado na Fazenda Periperi, Vitória da Conquista, Bahia, no período de junho a setembro de 2018. 


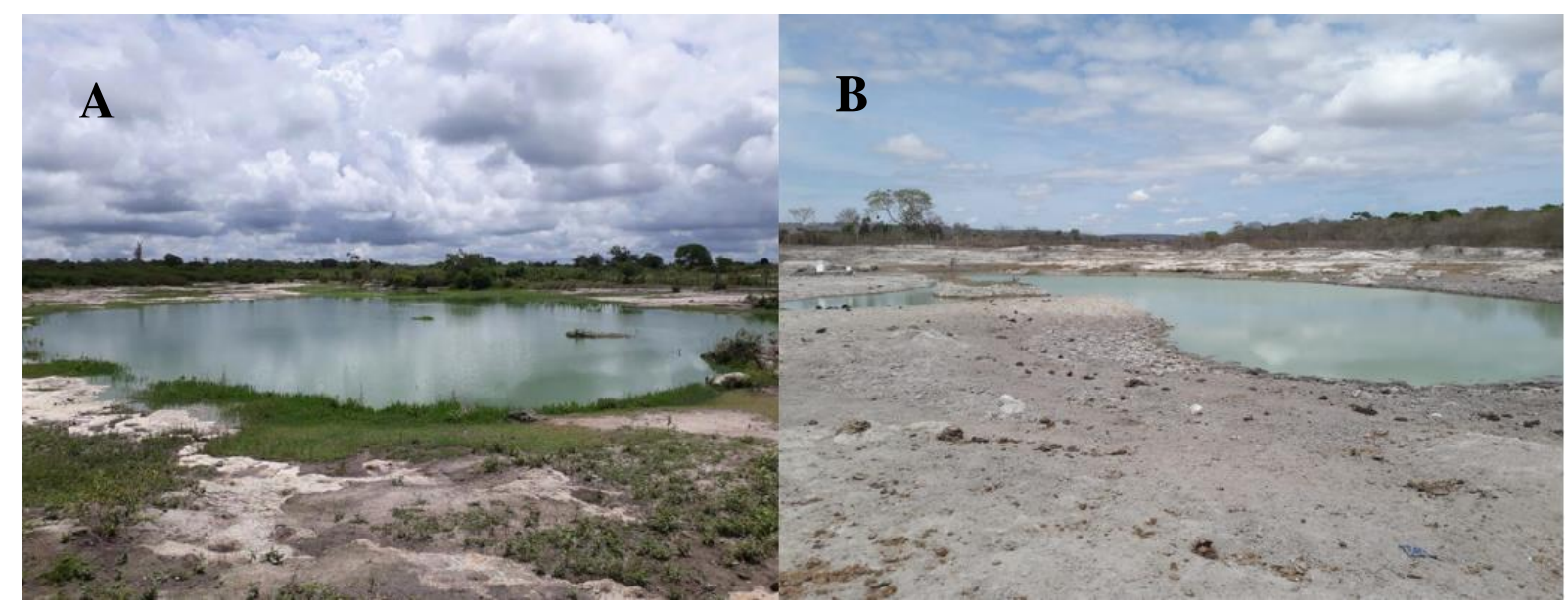

Figura 2: Corpo aquático amostrado na Fazenda Periperi, Vitória da Conquista, Bahia. A - Vista parcial do corpo aquático em junho de 2018; B -Vista parcial do corpo aquático em setembro de 2018.

\subsection{Estratégia amostral}

As coletas foram realizadas entre junho e setembro de 2018. Foram obtidas quinze amostras de plâncton por mês, distribuídos em cinco pontos, situadas ao longo do corpo aquático (Figura 1). As amostras das amebas testáceas no compartimento planctônico foram obtidas através da filtração de 20 litros de água por unidade amostral com auxílio de balde graduado. O volume de água amostrado foi padronizado levando em consideração a extensão e profundidade do corpo aquático. A água foi filtrada em rede de plâncton de $20 \mu \mathrm{m}$, acondicionado em frascos de polietileno de $150 \mathrm{ml}$ e fixadas com formaldeído a $4 \%$ de concentração final. Nos meses de agosto e setembro de 2018 foram obtidas 12 e 9 amostras de plâncton, respectivamente, devido a diminuição expressiva do volume de água do corpo aquático. Deste modo foram obtidas um total de 51 amostras de plâncton para todo o período do estudo.

As amostras de perifíton foram obtidas a partir da coleta das macrófitas aquáticas dos gêneros Pistia sp. e Salvinia sp. nos meses de junho e julho de 2018, visto que nos meses subsequentes o stand de macrófitas secou completamente. Para tanto as plantas foram obtidas com auxílio de bandejas plásticas (41 x $60 \times 15 \mathrm{~cm}$ ), as quais foram imersas abaixo das plantas flutuantes, delimitando assim a área da coleta. Em seguida, foi realizado o desprendimento do perifíton através da agitação destas plantas na água da bandeja, seguida da filtração (cerca de 5 litros desta água) com rede de abertura de malha de $20 \mu \mathrm{m}$ do lavado destas plantas e a fixação deste material com formol a $4 \%$ de concentração final $[36,37,38,39]$. Para cada tipo de macrófita foram coletadas 3 amostras por mês, totalizando 12 amostras perifíticas para este estudo.

\subsection{Análises físico-químicas e bacteriológicas da água}

As análises físicas e químicas foram realizadas in situ utilizando sondas paramétricas. Para a análise do potencial hidrogeniônico $(\mathrm{pH})$ utilizou-se o pHâmetro digital portátil com saída RS232 do fabricante Lutron Eletronic Enterprise ${ }^{\circledR}$. Para a temperatura da água (temp.) $\left({ }^{\circ} \mathrm{C}\right)$, condutividade elétrica $(\mathrm{CE})(\mu \mathrm{S} / \mathrm{cm})$ e sólidos totais dissolvidos (STD) (ppm) utilizou-se o medidor de multiparâmetro portátil com registro, do fabricante $\mathrm{AKSO}^{\circledR}$. Para o Oxigênio dissolvido (OD) (mg. $\left.\mathrm{L}^{-1}\right)$ foi utilizado o oxímetro digital com RS-232 e datalogger do fabricante Lutron Eletronic Enterprise ${ }^{\circledR}$. Para a determinação da transparência (transp.) (cm) foi utilizado o disco de Secchi e para a profundidade (prof.) $(\mathrm{cm})$ do local foi utilizada uma trena graduada de 3,0 metros.

Para as análises bacteriológicas (coliformes totais e termotolerantes), as amostras foram coletadas com frascos estéreis de $200 \mathrm{ml}$, acondicionadas em caixas isotérmicas (temperatura mantida entre $4^{\circ}$ e $10^{\circ} \mathrm{C}$ ) e encaminhadas até o Laboratório de Bacteriologia da Empresa Baiana de Águas e Saneamento S.A. (EMBASA) de Vitória da Conquista, Bahia. As análises foram 
realizadas no mesmo dia das coletas. Foi utilizado o teste Colilert ${ }^{\circledR}$ para estimar a contaminação bacteriológica expressa em Número Mais Provável (NMP).

Visando comparar os valores das variáveis obtidas nesse estudo com o que é preconizado para a qualidade da água foi utilizado a Resolução CONAMA 357/2005 [40], sendo considerado o corpo aquático como Classe 2 já que não existe um enquadramento oficial do mesmo.

\subsection{Análise e identificação das amebas testáceas}

As amostras foram previamente coradas com rosa de Bengala e analisadas em câmaras do tipo Sedgwick-Rafter sob microscópio óptico [30, 41]. Para estimar a abundância foram contadas apenas as amebas com protoplasma corado presentes em todo o fundo da câmara do tipo Sedgwick-rafter, o que indicava que as mesmas estavam vivas no momento da coleta [30, 42, 43].

Para a identificação das espécies, os espécimes foram montados em glicerina e sua identificação realizada com base em bibliografias pertinentes [19, 44, 45 - 60]. Foram realizadas fotomicrografias com auxílio do microscópio com câmera acoplada da marca Olympus ${ }^{\circledR}$ Modelo CX31RTSF.

A contagem dos organismos foi realizada através de 3 subamostragens da câmara do tipo Sedgwick-rafter [61]. Os taxa registrados no plâncton tiveram suas abundâncias expressadas em indivíduos $/ \mathrm{m}^{3}$ [62]. Já os taxa registrados associados às macrófitas aquáticas foram expressas em unidade de organismos/grama de peso seco da planta [8].

As amostras foram depositadas na Coleção Limnológica da Universidade Federal da Bahia, Campus Anísio Teixeira, Instituto Multidisciplinar em Saúde sob os números de tombo de 1081 a 1154 e 1165 .

\subsection{Análises estatísticas}

Foi determinado a frequência de ocorrência das espécies (FO) como a porcentagem das amostras em que determinada espécie ocorreu com relação ao total de amostras. A abundância relativa dos taxa (AR) foi calculada a partir do número de indivíduos da espécie por amostra analisada, em relação ao número total de indivíduos da amostra, sendo esta abundância relativa expressa em percentuais.

Foi verificada a normalidade dos dados com auxílio do teste de Kolmogorov-Smirnov. O teste de ANOVA foi realizado para verificar diferenças estatísticas significativas nas abundâncias das amebas que ocorreram no plâncton entre os meses de amostragem. Já para as abundâncias associadas as macrófitas utilizou-se o teste de Kruskal-Wallis. Estas análises estatísticas foram realizadas com o auxílio do software GraphPad Prism versão 5. Valores de $\mathrm{p}<0,05$ foram considerados significativos.

A técnica de escalonamento multidimensional não-métrico (NMDS) foi realizada, com o auxílio do programa Past versão 4.01, para avaliar a similaridade entre a ocorrência e abundância da comunidade de tecamebas entre os dois compartimentos (plâncton e perifíton) e as espécies de macrófitas avaliadas (Pistia sp. e Salvinia sp.). Para tanto apenas os dados de abundância relativa das espécies de amebas testáceas dos meses de junho e julho de 2018 foram utilizados. A matriz de similaridade foi calculada com dados obtidos a partir do índice de Bray-Curtis. A distorção da resolução é expressa pelo valor S (stress). Quanto mais próximo de zero for o valor de stress, melhor o ajuste entre a distância original dos dados amostrais e a configuração obtida pela análise [63].

\section{RESULTADOS}

\subsection{Parâmetros físico-químicos e bacteriológicos}

As variáveis obtidas no presente estudo indicaram que as águas do corpo aquático apresentam $\mathrm{pH}$ alcalino $(7,91 \pm 2,35)$ (média \pm desvio padrão), temperatura de $19,7 \pm 5,97^{\circ} \mathrm{C}$, condutividade elétrica de 1021,11 $\pm 547,09 \mu \mathrm{S} / \mathrm{cm}$, sólidos totais dissolvidos de 505,63 $\pm 253,89$ ppm, oxigênio 
dissolvido $1,75 \pm 0,31 \mathrm{mg} . \mathrm{L}^{-1}$, transparência da coluna d'água de $3,33 \pm 4,08 \mathrm{~cm}$ e profundidade $29,63 \pm 17,31 \mathrm{~cm}$. A Tabela 1 mostra as variáveis analisadas ao longo da amostragem.

Houve uma grande quantidade de coliformes totais encontrados ao longo de todo o período de coleta e em todas as amostras analisadas, sendo que os valores variaram de 3.550 a 241.960 $\mathrm{NMP} / 100 \mathrm{~mL}$, com média de 50.816,90 $\pm 68.138,12 \mathrm{NMP} / 100 \mathrm{~mL}$. Para os coliformes termotolerantes, avaliados pela pesquisa de Escherichia coli, os valores obtidos variaram entre 1 e $980 \mathrm{NMP} / 100 \mathrm{~mL}$, com média de 284,70 $\pm 278,88$ (Tabela 1).

\subsection{Composição de amebas testáceas}

Em todo o estudo foram registrados 32 taxa de amebas testáceas, representadas pelas famílias Arcellidae (três taxa), Centropyxidae (quatro taxa), Cryptodifflugiidae (um taxa), Difflugiidae (15 taxa), Euglyphidae (dois taxa), Netzeliidae (três taxa), Trigonopyxidae (um taxa) e Lesquereusiidae (três taxa) (Tabela 2). Algumas destas espécies estão ilustradas na Figura 3.

As espécies Arcella costata Ehrenberg, 1847, Ciclopyxis arcelloides Penard, 1902, Difflugia dragana Ogden \& Živković, 1983, Difflugia gigantea Schumlemberg, 1845, Difflugia kabylica Gauthier-Lièvre \& Thomas, 1958 e Difflugia helvetica Heuscher, 1885 são novas ocorrências para o estado da Bahia (Figura 4).

O plâncton apresentou a maior riqueza de taxa de amebas testáceas (23 taxa) quando comparado às macrófitas aquáticas (19 taxa). Difflugiidae (12 taxa) e Centropyxidae (quatro taxa) foram as famílias mais especiosas no plâncton, enquanto que Difflugiidae (dez taxa) e Lesquereusiidae (três taxa) foram as mais representativas associadas à Pistia sp e Difflugiidae (nove taxa) e Euglyphidae, Netzeliidae e Centropyxidae (dois taxa cada) para Salvinia sp. (Figura 5).

Os gêneros Difflugia sp., Centropyxis sp. e Arcella sp. apresentaram maior ocorrência no plâncton. Difflugia sp. e Euglypha sp. foram as mais especiosas em ambas os taxa de macrófitas, seguido de Netzelia sp. para Pistia sp. e Lesquereusia sp. para Salvinia sp. (Figura 6).

Considerando a frequência de ocorrência dos taxa registrados nas amostras de plâncton, as mais frequentes foram Arcella hemisphaerica (58,3\%), Difflugia limnetica (40\%) e Centropyxis aculeata (31,7\%). Nas amostras de Salvinia sp., Netzelia wailesi (83,3\%), D. limnetica, C. aculeata, Euglypha acanthophora, Difflugia elegans (66,7\% cada), A. hemisphaerica e Lesquereusia minor (50\% cada) foram as mais frequentes. Já nas amostras de Pistia sp., as espécies mais frequentes foram D. limnetica, C. aculeata, E. acanthophora, Difflugia gramen (66,7\% cada), seguidos de D. elegans e Lesquereusia spiralis (50\% cada) (Tabela 2). 


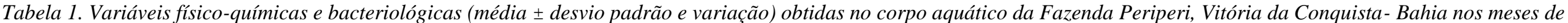

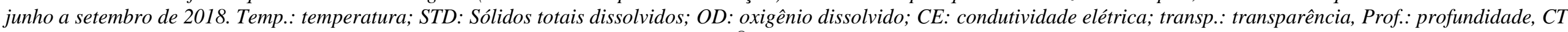

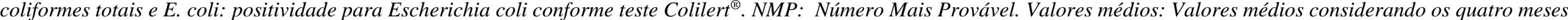
de coleta. Dados de algumas variáveis estabelecido pela resolução CONAMA 357/2005 para águas de classe 2.

\begin{tabular}{|c|c|c|c|c|c|c|c|}
\hline \multirow[t]{2}{*}{ Variáveis } & \multirow[t]{2}{*}{ Junho/2018 } & \multirow[t]{2}{*}{ Julho/2018 } & \multirow[t]{2}{*}{ Agosto/2018 } & \multirow[t]{2}{*}{ Setembro/2018 } & \multirow[t]{2}{*}{ Valores médios } & \multirow[t]{2}{*}{ Variação } & $\begin{array}{c}\text { Resolução CONAMA } \\
\text { 357/2005 } \\
\end{array}$ \\
\hline & & & & & & & Classe 2 \\
\hline $\mathrm{pH}$ & $9,12 \pm 0,35$ & $7,95 \pm 0,15$ & $8,42 \pm 0,16$ & $8,20 \pm 0,37$ & $7,91 \pm 2,35$ & $7,68-9,69$ & 6,0 a 9,0 \\
\hline Temp. $\left({ }^{\circ} \mathrm{C}\right)$ & $20,53 \pm 1,15$ & $20,20 \pm 1,47$ & $20,70 \pm 1,46$ & $21,76 \pm 1,27$ & $19,70 \pm 5,97$ & $19,21-25,6$ & Não Informado \\
\hline STD (ppm) & $393,67 \pm 93,87$ & $473,17 \pm 66,55$ & $683,80 \pm 159,77$ & $499,80 \pm 320,81$ & $505,63 \pm 253,89$ & $122-935$ & 500 \\
\hline OD (mg. $\left.\mathrm{L}^{-1}\right)$ & $1,52 \pm 0,40$ & $1,97 \pm 0,19$ & $1,64 \pm 0,16$ & $1,95 \pm 0,11$ & $1,75 \pm 0,31$ & $0,89-2,15$ & Não inferior a 5 \\
\hline $\mathrm{CE}(\mu \mathrm{S} / \mathrm{cm})$ & $731,33 \pm 199,65$ & $948,17 \pm 137,90$ & $1370,40 \pm 322,51$ & $1000,80 \pm 638,43$ & $1021,11 \pm 547,09$ & $253-1890$ & Não Informado \\
\hline Transp. (cm) & $4,67 \pm 2,07$ & $6,17 \pm 6,91$ & $3,00 \pm 2,12$ & $2,00 \pm 2,74$ & $3,33 \pm 4,08$ & $0-20$ & Não Informado \\
\hline Prof. (cm) & $39,33 \pm 19,47$ & $38,83 \pm 16,01$ & $26,60 \pm 12,93$ & $22,20 \pm 13,95$ & $29,63 \pm 17,31$ & $5,00-60,0$ & Não Informado \\
\hline CT (NMP/100 mL) & $39455 \pm 16246,95$ & $25403 \pm 2967,38$ & $123536 \pm 107311,91$ & $4210 \pm 933,38$ & $50816,90 \pm 68138,12$ & $3.550-\geq 241.960$ & Não Informado \\
\hline E. coli $(\mathrm{NMP} / 100 \mathrm{~mL})$ & $464 \pm 377,99$ & $211 \pm 66,16$ & $352 \pm 347,16$ & $111,8 \pm 107,97$ & $284,70 \pm 278,88$ & $\leq 1-980$ & $\leq 1000$ \\
\hline
\end{tabular}


A

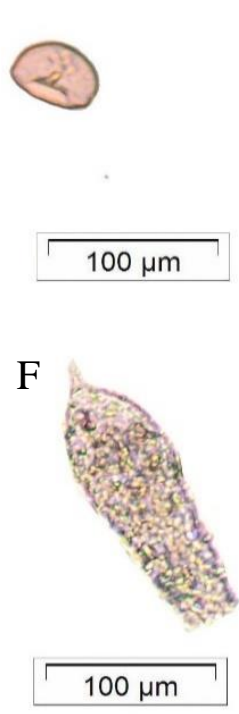

$\mathrm{K}$
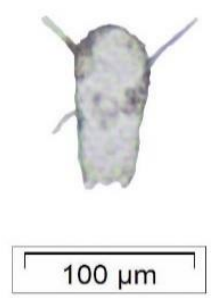

B

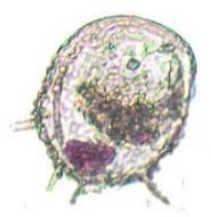

$100 \mu \mathrm{m}$

G
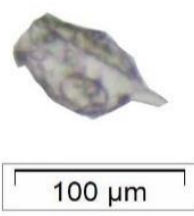

$\mathrm{L}$

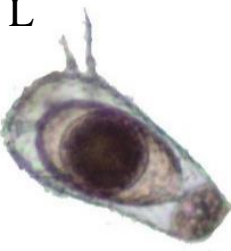

$100 \mu \mathrm{m}$
C

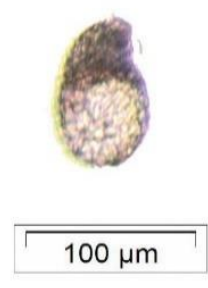

$\mathrm{H}$
$\mathrm{D}$

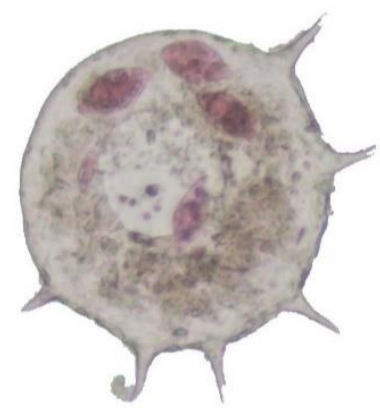

$\mathrm{E}$

$100 \mu \mathrm{m}$

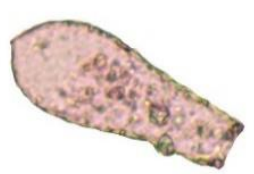

$100 \mu \mathrm{m}$

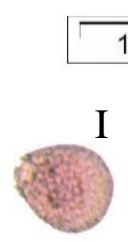

$100 \mu \mathrm{m}$

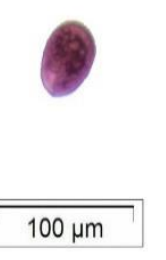

J

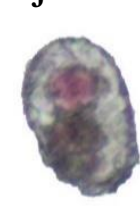

$100 \mu \mathrm{m}$

\section{M}

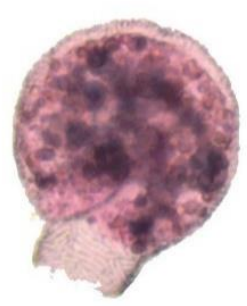

$\mathrm{N}$

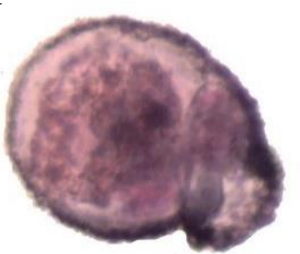

$100 \mu \mathrm{m}$
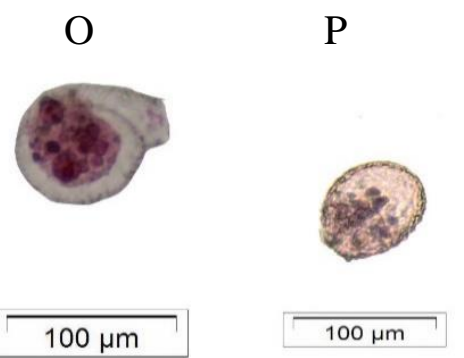

Q

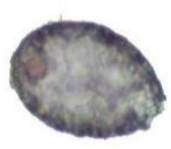

$100 \mu \mathrm{m}$

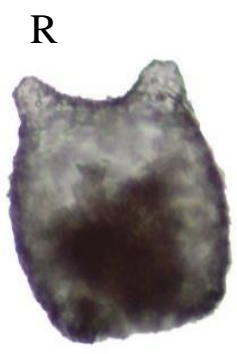

$\mathrm{S}$

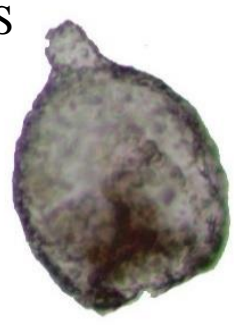

$100 \mu \mathrm{m}$

Figura 3: Fotomicrografias de alguns taxa de amebas testáceas registrados no corpo aquático da Fazenda do Periperi, Vitória da Conquista, Bahia. A: Arcella hemisphaerica; B: Centropyxis cassis; C: Centropyxis platystoma; D: Centropyxis aculeata; E: Cryptodifflugia oviformis; F: Difflugia acuminata; G: Difflugia elegans; H: Difflugia lanceolata; I: Difflugia gramen; J: Difflugia limnetica; K: Euglypha acanthophora;

L: Euglypha filifera var magna; $M$ : Lesquereusia spiralis; $N$ : Lesquereusia spiralis var arcuata; $O$ : Lesquereusia minor; P: Netzelia oviformis; Q: Netzelia wailesi; R e S: Netzelia corona. 
A

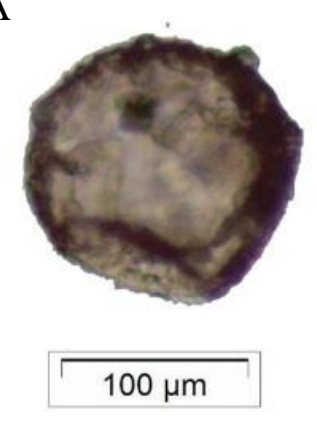

$\mathrm{D}$

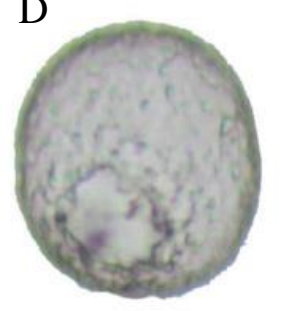

$100 \mu \mathrm{m}$
B

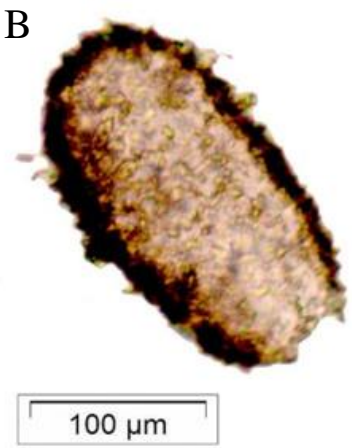

$\mathrm{E}$

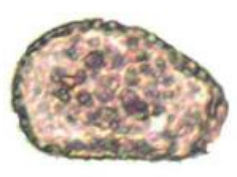

$100 \mu \mathrm{m}$

F

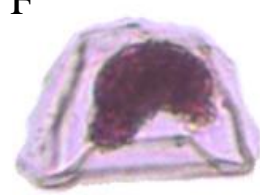

$100 \mu \mathrm{m}$

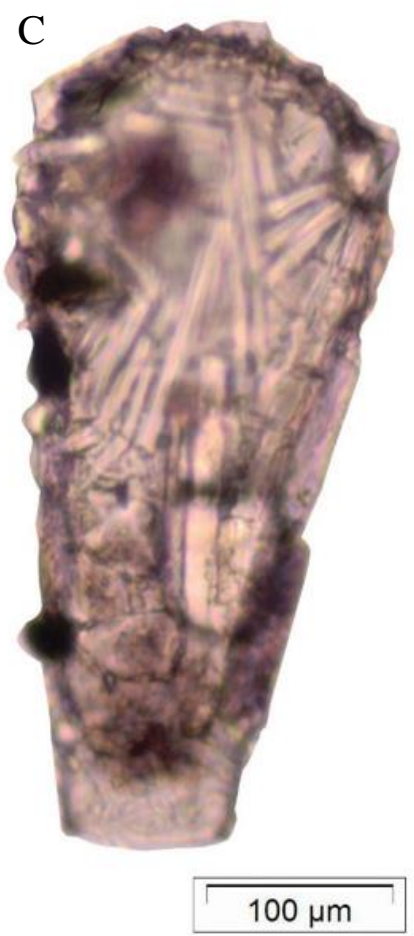

corpo aquaso da Fazenda epécies de amebas testáceas para o estado da Bahia, encontradas no corpo aquático da Fazenda do Periperi, Vitória da Conquista, Bahia. A: Ciclopyxis arcelloides; B: Difflugia dragana; C: Difflugia gigantea; D: Difflugia helvetica; E: Difflugia kabylica; F: Arcella costata. 
Tabela 2: Frequência de Ocorrência (FO) e Abundância relativa (AR) em porcentagem das espécies de amebas testáceas no plâncton e associados as macrófitas aquáticas Salvinia sp. e Pistia sp. no corpo aquático da Fazenda Periperi, Vitória da Conquista, Bahia. P: Plâncton, SV: Salvinia sp., PS: Pistia sp. *: novas ocorrências para o estado da Bahia.

\begin{tabular}{|c|c|c|c|c|c|c|c|c|c|c|c|}
\hline \multirow{3}{*}{ Taxa } & \multicolumn{8}{|c|}{ AR (\%) } & \multicolumn{3}{|c|}{ FO $(\%)$} \\
\hline & \multicolumn{3}{|c|}{ Jun/18 } & \multicolumn{3}{|c|}{ Jul/18 } & \multirow{2}{*}{\begin{tabular}{|c|} 
Ago/18 \\
$P$
\end{tabular}} & \multirow{2}{*}{\begin{tabular}{|c|} 
Set/18 \\
$P$ \\
\end{tabular}} & \multirow{2}{*}{$\mathbf{P}$} & \multirow{2}{*}{ SV } & \multirow{2}{*}{ PS } \\
\hline & $\mathbf{P}$ & SV & PS & \begin{tabular}{l|l}
$\mathbf{P}$ \\
\end{tabular} & SV & PS & & & & & \\
\hline \multicolumn{12}{|l|}{ Arcellidae Ehrenberg, 1830} \\
\hline *Arcella costata Ehrenberg, 1847 & 0,5 & & & 6,3 & & & & & 1,6 & & \\
\hline $\begin{array}{l}\text { Arcella gibbosa var mitriformis Deflandre, } \\
1928\end{array}$ & & & & & & & 8,9 & 1,2 & 3,3 & & \\
\hline Arcella hemisphaerica Perty, 1852 & 85,1 & 0,6 & & 41,1 & 0,9 & 0,4 & & 3,5 & 58,3 & 50,0 & 33,3 \\
\hline \multicolumn{12}{|l|}{ Centropyxidae Deflandre, 1953} \\
\hline Centropyxis aculeata (Ehrenberg, 1838) & 5,6 & 13,2 & 28,8 & 6,3 & 19,3 & 3,7 & 2,9 & 8,1 & 31,7 & 66,7 & 66,7 \\
\hline Centropyxis cassis (Wallich, 1864) & 0,5 & & & & & & 6,4 & 4,1 & 8,3 & & \\
\hline Centropyxis hirsuta Deflandre, 1929 & & 0,5 & & & & & 0,8 & 0,6 & 1,6 & 16,7 & \\
\hline Centropyxis platystoma (Pénard, 1902) & & & & & & & & 1,7 & 6,7 & & \\
\hline \multicolumn{12}{|l|}{ Cryptodifflugiidae Jung, 1942} \\
\hline Cryptodifflugia oviformis Penard, 1902 & 3,0 & & & & & & 0,5 & & 1,6 & & \\
\hline \multicolumn{12}{|l|}{ Difflugiidae Awerintzew, 1906} \\
\hline $\begin{array}{l}\text { Cucurbitella madagascariensis Gauthier- } \\
\text { Lievrè \& Thomas, } 1980\end{array}$ & 3,0 & 0,5 & & & 3,1 & 0,7 & 0,5 & & 3,3 & 16,7 & 33,3 \\
\hline Difflugia acuminata Ehrenberg, 1838 & & & & & 3,1 & 0,5 & 2,0 & 5,2 & 8,3 & 33,3 & 33,3 \\
\hline $\begin{array}{l}\text { Difflugia corona var ecornis Gauthier-Lievrè } \\
\& \text { Thomas, } 1958\end{array}$ & & & 2,2 & & & & 10,9 & & & & 16,7 \\
\hline *Difflugia dragana Ogden \& Živković, 1983 & & & & 11,6 & & & & & 1,6 & & \\
\hline Difflugia elegans Pénard, 1890 & & 2,2 & & & 4,1 & 3,6 & & & 5,0 & 66,7 & 50,0 \\
\hline Difflugia gramen Pénard, 1902 & & 1,5 & 16,5 & & 13,7 & 8,3 & 1,5 & 8,6 & 18,3 & 33,3 & 66,7 \\
\hline Difflugia gigantea Schumlemberg, 1845 & & & & & & 0,2 & & & & & 16,7 \\
\hline Difflugia helvetica Heuscher, 1885 & & & & & 0,9 & 0,8 & & & & 33,3 & 33,3 \\
\hline $\begin{array}{l}\text { *Difflugia kabylica Gauthier-Lièvre \& } \\
\text { Thomas, } 1958\end{array}$ & & 1,0 & & & & & 1,5 & & 1,6 & & \\
\hline Difflugia lanceolata Pénard, 1890 & 0,5 & & & & & & & 0,0 & 1,6 & & \\
\hline Difflugia limnetica Levander, 1900 & 0,9 & 11,6 & 2,2 & 34,7 & 13,7 & 15,6 & 55,5 & 58,3 & 40,0 & 66,7 & 66,7 \\
\hline Difflugia lithophila Pénard, 1902 & & & & & & & 0,5 & & 1,6 & & \\
\hline Difflugia lobostoma Leidy, 1879 & 0,5 & & & & & & 1,0 & & 3,3 & & \\
\hline Difflugia schuurmani Van Oye, 1932 & & 0,5 & & & 1,6 & 3,1 & & 2,9 & 6,7 & 33,3 & 33,3 \\
\hline $\begin{array}{l}\text { Pentagonia maroccana Gauthier-Lièvre \& } \\
\text { Thomas, } 1958\end{array}$ & & & & & 2,4 & & 1,5 & 4,1 & 8,3 & 16,7 & 0,0 \\
\hline \multicolumn{12}{|l|}{ Euglyphidae Wailes, 1919} \\
\hline Euglypha acanthophora (Ehrenberg, 1840) & & 51,3 & 31,7 & & 9,5 & 53,4 & 3,9 & 1,2 & 16,7 & 66,7 & 66,7 \\
\hline Euglypha filifera var magna Penard, 1890 & & 1,1 & 7,7 & & 1,6 & & & & 5,0 & 33,3 & \\
\hline \multicolumn{12}{|l|}{ Netzeliidae Kosakyan et al., 2016} \\
\hline Netzelia corona (Wallich, 1864) & & & & & & & & 0,6 & 1,6 & & \\
\hline Netzelia oviformis (Cash, 1909) & & & & & 16,8 & 1,5 & 1,5 & & 1,6 & 33,3 & 16,7 \\
\hline Netzelia wailesi (Ogden, 1980) & & 10,2 & 7,7 & & 5,1 & 5,8 & & & 5,0 & 83,3 & 16,7 \\
\hline \multicolumn{12}{|l|}{ Trigonopyxidae Loeblich \& Tappan, 1964} \\
\hline Ciclopyxis arcelloides Pénard, 1902 & 0,5 & & & & & & & & 1,6 & & \\
\hline \multicolumn{12}{|l|}{ Lesquereusiidae Jung, 1942} \\
\hline Lesquereusia spiralis (Ehrenberg, 1840) & & & & & 2,4 & 1,9 & & & 1,6 & 16,7 & 50,0 \\
\hline $\begin{array}{l}\text { Lesquereusia spiralis var arcuata Gauthier- } \\
\text { Lièvre \& Thomas, } 1960\end{array}$ & & & & & & 0,2 & & & & 16,7 & \\
\hline Lesquereusia minor Walton, 1930 & & 5,7 & 3,0 & & 1,9 & 0,4 & & & 1,6 & 50,0 & 33,3 \\
\hline
\end{tabular}


Nove espécies de amebas testáceas ocorreram exclusivamente associadas às macrófitas aquáticas (D. elegans, D. gigantea, D. helvetica, Euglypha filifera var magna, L. spiralis, Lesquereusia spiralis var arcuata, L. minor, Netzelia oviformis e N. wailesi). Dez taxa de tecamebas foram encontrados associados tanto em macrófitas aquáticas quanto em amostras de plâncton (Arcella gibbosa var mitriformis, C aculeata, Centropyxis hirsuta, Cucurbitella madagascariensis, Difflugia acuminata, D. gramen, D. limnetica, Difflugia schuurmani, Pentagonia maroccana e E. acanthophora) (Tabela 2).

As espécies de D. gigantea e $L$. spiralis var arcuata ocorreram exclusivamente associadas à Pistia sp. durante todo o período em estudo. Em Salvinia sp. três taxa (C. hirsuta, Difflugia kabylica e P. maroccana) ocorreram exclusivamente associadas a esta macrófita durante a sua permanência no corpo aquático. Entretanto, estas espécies registradas em Salvinia sp. foram posteriormente verificadas ocupando o plâncton (Tabela 2).

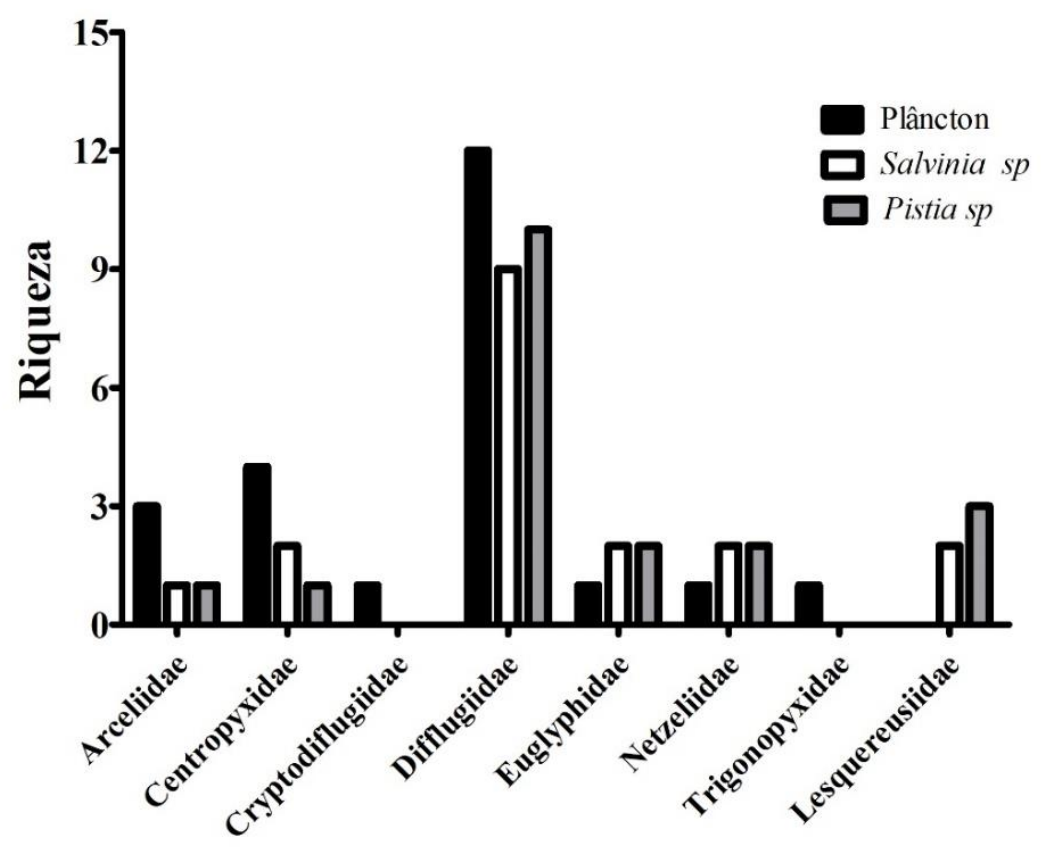

Figura 5: Riqueza das famílias de amebas testáceas no plâncton e macrófitas aquáticas (Salvinia sp.e Pistia sp.) no corpo aquático da fazenda Periperi, Vitória da Conquista-Bahia.

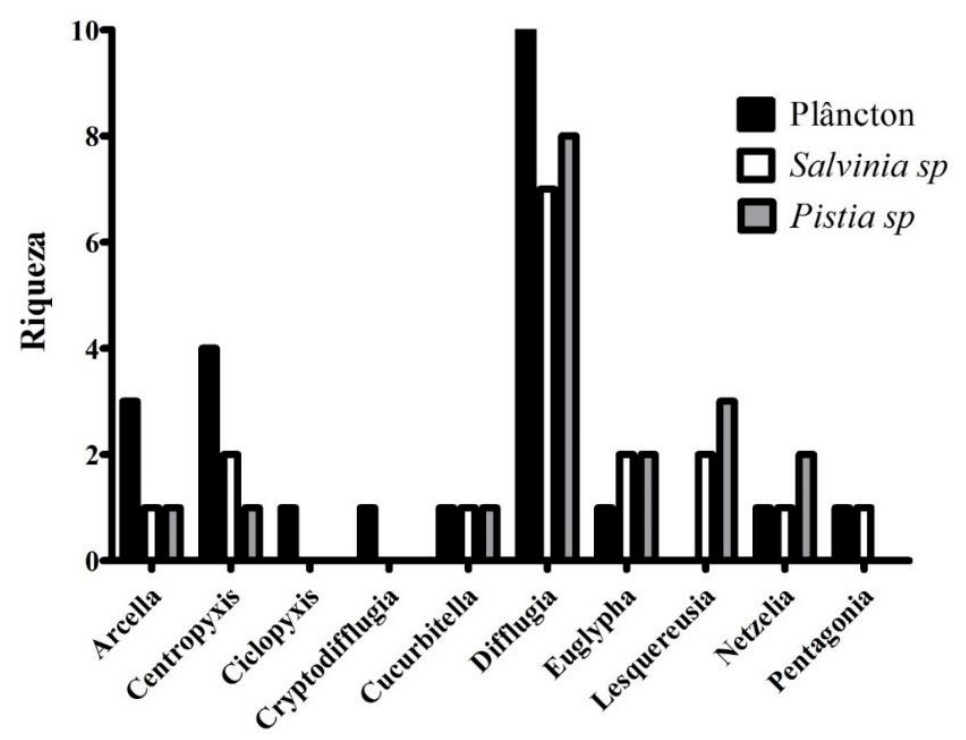

Figura 6: Riqueza dos gêneros de amebas testáceas no plâncton e perifiton (Salvinia sp. e Pistia sp.) no corpo aquático da fazenda Periperi, Vitória da Conquista- Bahia. 


\subsection{Abundância de amebas testáceas}

A abundância (média e desvio padrão) das amebas testáceas no compartimento planctônico variou entre os meses de coleta, sendo os valores mais elevados registrados em junho (12,23 \pm $11,24)$, seguido de agosto $(11,22 \pm 8,88)$, setembro $(9,61 \pm 5,77)$ e julho $(0,89 \pm 0,60)$. Entretanto, não houve diferença estatística significativa $(\mathrm{F}=2,264 ; \mathrm{p}=0,09)$ (Figura 7).

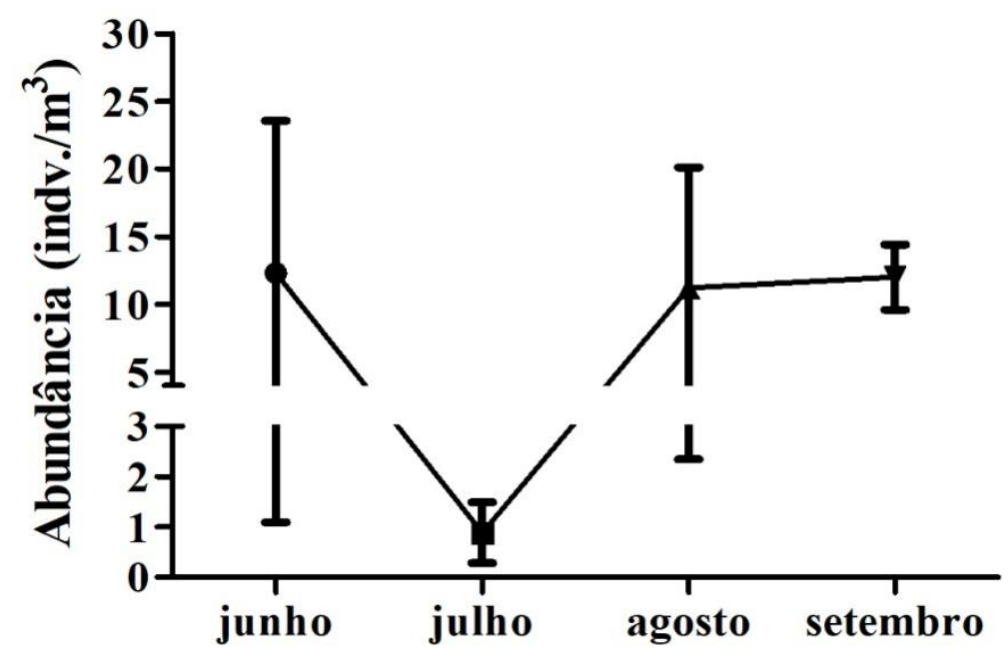

Figura 7: Abundância (Indv/ $\mathrm{m}^{3}$ ) (média \pm desvio padrão) das amebas testáceas no plâncton do corpo aquático da fazenda Periperi, Vitória da Conquista, Bahia.

A abundância (média e desvio padrão) das amebas testáceas associadas a macrófitas aquáticas variou de acordo com os meses e o gênero de plantas estudadas. Para o mês de junho de 2018 as maiores abundâncias foram registradas em Salvinia sp. $(95,38 \pm 68,52)$. Contudo, no mês subsequente as amostras de Pistia sp. exibiram as maiores densidades de amebas $(153,17 \pm 88,93)$. Estas diferenças encontradas não foram estatisticamente significativas $(K=7.513 ; \mathrm{p}=0,06)$ (Figura 8).

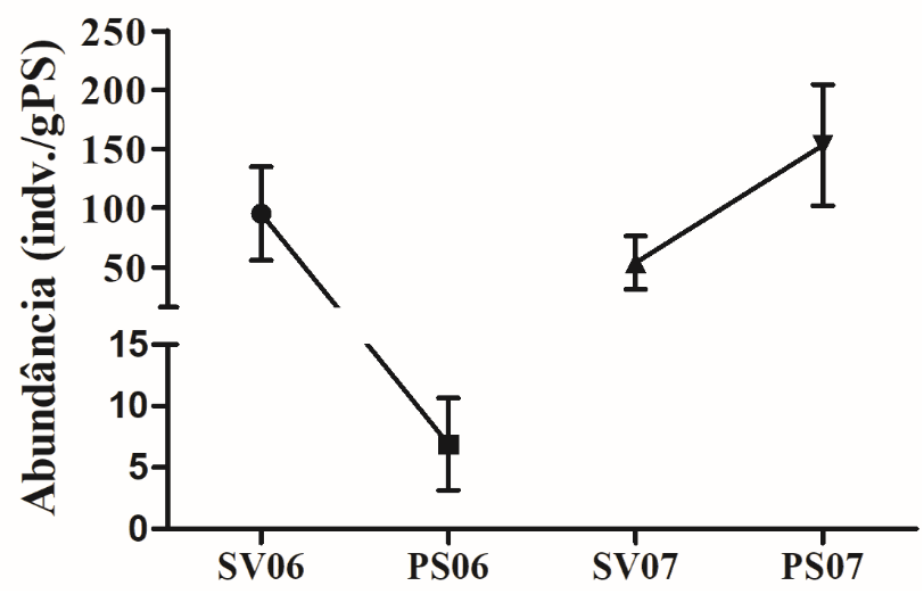

Figura 8: Abundância (Indv./gPS) das amebas testáceas associadas às macrófitas aquáticas na fazenda Periperi, Vitória da Conquista, Bahia. SV06: Salvinia sp. em Junho/2018; SV07: Salvinia sp. em Julho/2018; PS06: Pistia sp. em Junho/2018; PS07:Pistia sp. em Julho/2018.

Os taxa mais abundantes nas amostras de plâncton foram: A. hemisphaerica com maior abundância em junho, seguida de $C$. aculeata (junho e agosto) e $D$. limnetica (agosto e setembro) (Tabela 2). Para o perifíton, os taxa mais abundantes foram E. acanthophora em junho e julho, seguido de $C$. aculeata em junho (maior abundância em Salvinia sp.) e julho (maior abundância em Pistia sp.), N. wailesi em junho e julho (demonstrando a mesma abundância em Pistia sp. e Salvinia sp.) e Netzelia oviformis somente em julho (maior abundância em Salvinia sp.), como observado na Tabela 2. 
A análise de escalonamento multidimensional não-métrica (NMDS) evidenciou distintos padrões de ocorrência e abundância relativa de amebas testáceas para cada compartimento amostrado (Figura 9).

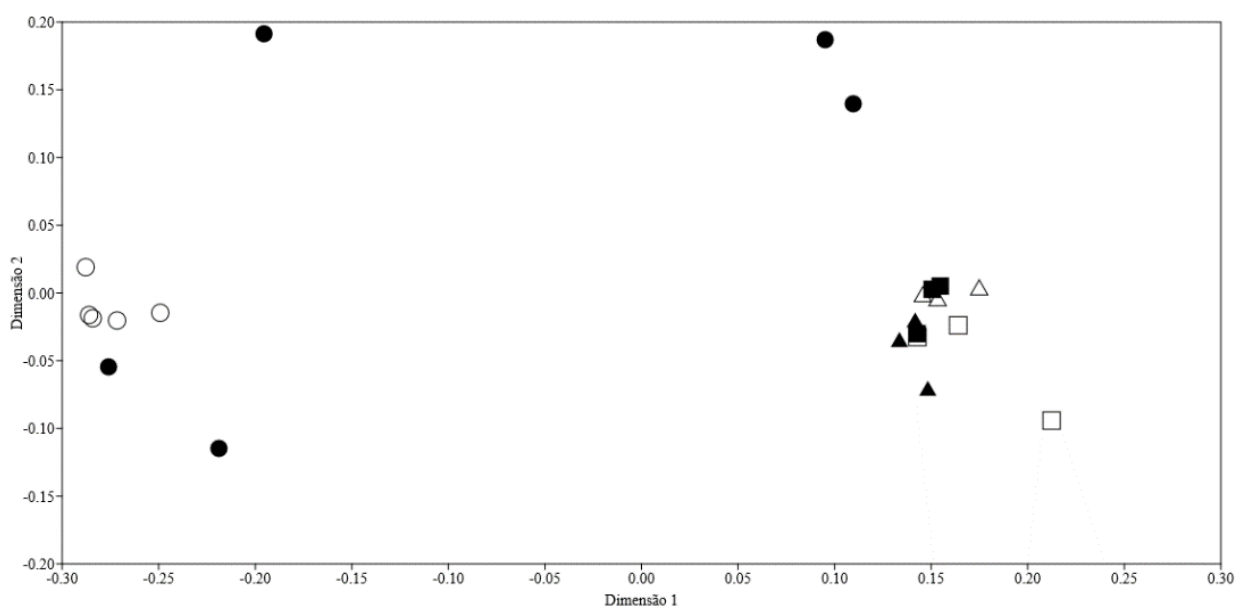

Figura 9: Escala multidimensional não-métrica (NMDS) obtida a partir dos dados de ocorrência e abundância relativa de amebas testáceas dos diferentes compartimentos do corpo aquático da Fazenda Periperi, Vitória da Conquista, Bahia (stress =0, 1313). Quadrados: Pistia sp., Triângulos: Salvinia sp. e Círculos: Plâncton. Símbolos vazios mês de junho/2018, símbolos cheios mês de julho/2018.

\section{DISCUSSÃO}

As variáveis físico-químicas e bacteriológicas analisadas indicam que o ambiente em questão é eutrofizado, reforçados sobretudo pelos baixos valores de transparência da água e de oxigênio dissolvido, evidenciando o processo de degradação do solo [64, 65]. Este cenário reflete elevados teores de matéria orgânica cuja depuração acarreta em reduções nos teores de oxigênio dissolvido [66]. Adicionalmente, a água da lagoa apresentou coloração bem esverdeada durante todos os meses de coleta, refletindo assim a elevada biomassa fitoplanctônica, com predomínio de cianobactérias e algas verdes filamentosas.

Outros parâmetros como condutividade elétrica, sólidos totais dissolvidos, coliformes totais e E. coli indicam grau de eutrofização e contaminação fecal do corpo aquático em estudo. A condutividade elétrica indica a quantidade de sais existentes na coluna d'água [67] e representa uma medida indireta da concentração de poluentes, com níveis superiores a $100 \mu \mathrm{S} / \mathrm{cm}$ sendo indicador de ambiente eutrófico [68]. O valor mínimo de condutividade observado no presente estudo foi de $253 \mu \mathrm{S} / \mathrm{cm}$. Os elevados valores de sólidos totais dissolvidos também indicam impactos na água [69]. A resolução do CONAMA 357/2005 [40] estabelece que para as classes 1 a 3 o valor de STD deve ser até $500 \mathrm{ppm}$, nesse estudo a média de STD ultrapassou o limite estabelecido pela resolução.

Os valores de coliformes totais e termotolerantes encontrados demonstraram que todas as amostras estavam contaminadas por coliformes, indicando assim contaminação fecal recente, visto que Escherichia coli sobrevive pouco tempo no ambiente [66, 70]. Além disso, a passagem e permanência de animais pelo ambiente também pode ser considerada como um fator determinante para a concentração de coliformes [71, 72]. Durante as coletas foram encontradas grandes quantidades de fezes animais nas margens do corpo aquático e a presença de cavalos, o que pode ser umas das principais fontes de contaminação deste corpo aquático.

Avaliando estes dados com relação aos parâmetros bacteriológicos estabelecidos pela Resolução Conama n $357 / 2005$ [40], é evidente que há um comprometimento da qualidade da água para consumo humano, visto que houve a presença de coliformes termotolerantes em todas as amostras analisadas, o que as tornam impróprias para esta finalidade. Contudo, considerando que a destinação principal destas águas é a dessedentação de animais, classe 2, o ambiente pode ser considerado como apropriado para esta finalidade. Porém, vale ressaltar que as cianobactérias são capazes de liberar toxinas, que comprometem a vida aquática e a dos que têm ligação com as mesmas, podendo causar alterações hepáticas, neurológicas e motoras nos animais que ingerem água contaminada [73]. 
Quanto as amebas testáceas, houve variação da riqueza e abundância destes organismos registrada nos biótopos distintos, sendo notável a maior riqueza nas amostras planctônicas quando comparadas as macrófitas aquáticas. Estes achados divergem da literatura $(15,17,18,22,42,74$, 75]. A zona litorânea, em específico as macrófitas aquáticas, conferem elevada produtividade, maior heterogeneidade ao ambiente, disponibilidade de alimento e espaço para esses organismos, exibindo assim o maior número de taxa quando comparado ao plâncton [76]. Entretanto, tal divergência pode ser explicada pela diferença amostral, visto que o número de amostras perifíticas foi menor devido ao desaparecimento destas plantas no corpo aquático ao longo dos meses de coleta.

As famílias mais especiosas neste trabalho (Difflugiidae, Arcellidae e Centropyxidae) são comumente registradas em diversos sistemas aquáticos brasileiros com distintos graus de trofia [13$15,17,18,22,24,30,60]$. A elevada riqueza de Difflugiidae tanto nas macrófitas quanto no plâncton evidencia que seus representantes podem ocorrer em diferentes hábitats [18].

A família Euglyphidae apresentou elevada ocorrência nas amostras associadas as macrófitas aquáticas, o que pode ser explicado por suas carapaças serem compostas de substâncias hialinas, o que confere uma maior vulnerabilidade do protoplasma desses organismos quando se expõem diretamente à luz, o que ocorreria nas amostras do plâncton [22].

As amebas registradas nas amostras de plâncton possuíram carapaças esféricas ou hemisféricas, as quais são mais hidrodinâmicas e facilmente adaptadas a região limnética, cuja a necessidade de resistir ao fluxo de água é menor. Por outro lado, as registradas nas macrófitas possuíam tecas alongadas e achatadas, formas menos hidrodinâmicas e que, portanto, necessitam de uma menor demanda energética, já que este biótopo é mais estável e estruturado [24].

Algumas espécies que ocorreram em um mês exclusivamente associadas as macrófitas aquáticas (Centropyxis hirsuta, Difflugia kabylica e Pentagonia maroccana), após a ausência das plantas, foram registradas posteriormente nas amostras de plâncton. Estes achados evidenciam a plasticidade destes organismos para colonizarem biótopos distintos, apresentando mecanismos fisiológicos para regular a sua flutuação na coluna d'agua, a exemplo de vacúolos de gás [24], conferindo assim vantagem adaptativa para persistirem a ambientes aquáticos instáveis, a exemplo de lagoas temporárias na região semiárida. Essas diferenças qualitativas na composição e abundância relativa entre os compartimentos foram evidenciadas através da análise de NMDS, confirmando os achados apresentados.

A. hemisphaerica, C. aculeata, D. limnetica e E. acanthophora em geral foram as mais importantes numericamente na área de estudo. Estas são comuns em ambientes com elevada taxa de matéria orgânica $[8,32,77]$ e contaminação ambiental. As amebas podem ser consideradas como polífagas, ou seja, se alimentam de vários grupos de organismos, principalmente de bactérias e microalgas [8]. Logo em ambientes eutróficos e contaminados por dejetos, como a área do presente estudo, há elevadas biomassas bacterianas e fitoplanctônicas que propiciam a proliferação de algumas espécies de amebas testáceas tolerantes a estas condições ambientais, a exemplo das espécies mais abundantes neste estudo. Ressalta-se que algumas espécies de amebas testáceas podem controlar a abundância de cianobactérias (Microcystis sp.) durante florações algais [78].

Em geral, diversos estudos demonstram que a estrutura e composição das assembleias de protistas são significativamente alteradas com o aumento da eutrofização, onde a abundância e biomassa destes organismos são maiores em ambientes eutróficos quando comparados a ambientes oligotróficos $[79,80,81,82]$. Neste sentido, as espécies aqui registradas para o corpo aquático estudado indicam que toleram as condições ambientais registradas, isto é processo de eutrofização com contaminação por dejetos.

Do ponto de vista da bioindicação ambiental, não existe na literatura um protocolo com listagem de táxons característicos de ambientes contaminados, sendo que qualquer afirmativa neste sentido requer cautela. Estudo na bacia do Rio Peruaçú em Minas Gerais [83], elencou "táxons referências" como espécies típicas de ambientes mais preservados ou mais impactados, baseado na ocorrência das espécies nos diversos habitats estudados (preservados e pouco preservados). Assim, as espécies Arcella discoides, A. hemisphaerica, Centropyxis aculeata, C. cassis, Difflugia corona, D. gramen, D. lobostoma, que também ocorreram no presente estudo, foram consideradas como táxons "referências" de ambientes pouco preservados na bacia do rio Peruaçu (MG) [83]. Por outro lado, as espécies Arcella costata e Lesquereusia minor foram consideradas pela mesma autora como "referências" de ambientes mais preservados na bacia do rio Peruaçu. Entretanto, estas mesmas espécies ocorreram no presente estudo. Estes resultados sugerem que a determinação de taxa bioindicadores deve ser realizada com parcimônia e maior embasamento científico, pois os estudos 
destes organismos no Brasil são escassos, considerando principalmente a quantidade e diversidade de corpos aquáticos no pais, o que reflete no desconhecimento dos requerimentos ecológicos e tolerâncias das espécies que aqui ocorrem.

O número de taxa de amebas testáceas aqui registrados é expressivo para o tipo de ambiente estudado. Pesquisa sobre o zooplâncton em 8 lagoas temporárias nos municípios de Urucuia e Lagoa Grande, Minas Gerais, registrou apenas 3 espécies de amebas testáceas (Arcella mitrata, Difflugia corona e Difflugia oblonga) presentes em 2 das lagoas [33]. Esta diferença nas riquezas registradas entre o presente estudo e o citado acima [33] pode estar relacionada, dentre outros fatores, a trofia do ambiente (lagoas oligotróficas) e com as metodologias de coleta das amostras, cujo o tamanho da abertura de malha da rede de plâncton usada em Minas Gerais foi de $68 \mu \mathrm{m}$, não sendo assim adequado para o grupo, subestimando a riqueza destes organismos, conforme apontam as próprias autoras. Comparações entre o presente estudo com outros trabalhos envolvendo ambientes temporários tornam-se difíceis, visto que são escassas as investigações envolvendo lagoas temporárias e as amebas testáceas. Geralmente os trabalhos são restritos a rotíferos, cladóceros e copépodes.

Analisando os resultados obtidos neste levantamento com os já publicados para o estado da Bahia em ambientes dulcícolas, a riqueza aqui relatada é a segunda maior registrada, estando atrás apenas para a do rio Cachoeira [30]. Comparando com outro ambiente lêntico e eutrófico, reservatório povoado Olhos D'água do Souza, Glória- Bahia [32], o corpo aquático da Fazenda Periperi apresentou um número cerca de 10 vezes maior de amebas testáceas. Além das características ecológicas, físicas e químicas peculiares a estes ambientes, a diferença da riqueza registrada pode também ser atribuída a metodologia de amostragem, sendo que no reservatório da Glória utilizou-se malha de $64 \mu \mathrm{m}$. A malha de $20 \mu \mathrm{m}$, utilizada no presente estudo, permite reter uma gama maior de organismos amebóides quando comparada ao de $64 \mu \mathrm{m}$, possibilitando assim uma amostragem mais significativa da comunidade.

Os novos registros de ocorrência para o estado da Bahia (Arcella costata, Ciclopyxis arcelloides, Difflugia dragana, Difflugia gigantea, Difflugia kabylica e Difflugia helvetica) elevam o procta de amebas testáceas do estado para 129 taxa.

\section{CONCLUSÃO}

O corpo aquático estudado é um ambiente eutrofizado, contaminado por dejetos de animais, cujas as variáveis limnológicas e bacteriológicas analisadas indicam que suas águas são impróprias para consumo humano, porém adequadas para dessedentação de animais. A riqueza das amebas testáceas registradas neste trabalho (32 taxa) foi expressiva para ambiente temporários, efêmeros e contaminados por dejetos. Deste modo, as espécies inventariadas no corpo aquático da Fazenda Periperi são tolerantes a estas condições ambientais (eutrofização e contaminação fecal). O biótopo que apresentou a maior riqueza foi o plâncton.

Alguns organismos foram somente observados nas amostras de plâncton, bem como para macrófitas aquáticas (Salvinia sp. e Pistia sp). Houve também intercambio espacial de protistas entre os biótopos, após o desaparecimento das macrófitas promovido pela seca, demonstrando a plasticidade destes organismos frente às adversidades encontradas em lagoas temporárias típicas do semiárido brasileiro, ambientes estes instáveis e sazonais. Esta pesquisa contribui para o levantamento de amebas testáceas no estado Bahia, incluindo seis novos registros. Estudos adicionais para a região semiárida devem ser intensificados, de modo a revelar a biodiversidade ainda tão negligenciada das amebas testáceas e suas estratégias de colonização e permanência nestes ambientes aquáticos efêmeros.

\section{AGRADECIMENTOS}

Ao senhor Normando proprietário da fazenda Periperi por permitir a realização das coletas, a Empresa Baiana de Água e Saneamento EMBASA, em especial aos Biólogos Elly Rogério Sampaio de Souza e Eliene Campos Macedo pelo apoio e suporte nas análises bacteriológicas. Ao Biólogo Valber Dias, aos motoristas da UFBA e os estagiários pelo auxílio nas coletas. Aos revisores pela leitura crítica do manuscrito e sugestões. 


\section{REFERÊNCIAS BILIOGRÁFICAS}

1. Souza MBG. Tecamebas (Protozoa, Rhizopoda) associadas às macrófitas aquáticas da bacia do rio Jequitinhonha: Parque Estadual do Rio Preto e Parque Estadual do Grão Mogol, MG. Unimontes Cient. 2005;7(2):129-142.

2. Booth RK. Ecology of testate amoebae (Protozoa) in two lake superior coastal wetlands: implications for paleoecology and environmental monitoring. Wetlands. 2001;21(4):564-76, doi: 10.1672/02775212(2001)021[0564:EOTAPI]2.0.CO;2

3. Corliss JO. Biodiversity and biocomplexity of the protists and an overview of their significant roles in mantenance of four biosphere. Acta Protozool. 2002;41:199-219.

4. Miranda VBS, Mazzoni, R. Testate amoebae (Protozoa Rhizopoda) in two biotopes of Ubatiba stream, Maricá, Rio de Janeiro State. Acta Sci Biol Sci. 2015;37(3):291-299, doi: 10.4025/actascibiolsci.v37i3.28087

5. Smith HG, Bobrov A, Lara E. Diversity and biogeography of testate amoebae. Biodivers Conserv. 2015;17:329-343, doi: 10.1007/s10531-007-9260-9

6. Dantas- Silva LT, Dantas EW. Zooplâncton (Rotifera, Cladocera e Copepoda) e a eutrofização em reservatórios do nordeste brasileiro. Oecol Australis. 2013;17(2):53-58.

7. Fragoso Júnior CR, Tucci CEM, Collischonn W, Marques DMLM. Simulação de eutrofização em lagos rasos II: Sistema do Taim (RS). Rev Bras Recur Hídricos. 2007;12:37-48.

8. Silva MB. Assembléias de amebas testáceas (Amoebozoa: Rhizopoda) associadas a rizosfera de Eichhornia crassipes (Martius) Solomons (Pontederiaceae) no Rio Cachoeira, Bahia. [dissertação] Ilhéus (BA): Universidade Estadual de Santa Cruz. UESC; 2008. 115 p.

9. Arndt H. A critical review of the importance of rhizopods (naked and testate amoebae) and actinopods (heliozoan) in lake plankton. Marine Microbial Food Webs. 1993;7(1):3-29.

10. Gilbert D, Amblard C, Bourdier G, Francez AJ. The microbial loop at the surface of a peatland: Structure, Function and Impact of nutrient input. Microb Ecol. 1998;35:83-93.

11. Mitchel EAD, Bocard D, Buttler AJ, Grosvernier P, Gilbert D, Gobat JM. Structure of microbial communities in Sphagnum peatlands and effects of atmospheric carbon dioxide enrichment. Microb Ecol. 2003;16:187-199.

12. Lansac-Tôha FA, Velho LFM, Costa DM, Simões NR, Alves GM. Structure of the testate amoebae community in diferent habitats in a neotropical floodplain. Braz J Biol. 2014;74(1):181-190, doi: 10.1590/1519-6984.24912

13. Velho LFM., Lansac-Tôha FA, Serafim-Júnior M. Testate Amoebae (Rhizopodea-Sarcodina) from zooplankton of the High Paraná River floodplain, State of Mato Grosso do Sul, Brazil: I. Families Arcellidae and Centropyxidae. Stud Neotrop Fauna E. 1996;31(1):35-50, doi: 10.1076/snfe.31.1.35.13315

14. Velho LFM, Lansac-Tôha FA. Testate Amoebae (Rhizopodea-Sarcodina) from zooplankton of the High Paraná River floodplain, State of Mato Grosso do Sul, Brazil: II. Family Difflugiidae. Stud Neotrop Fauna E. 1996;31(3-4):179-192, doi: 10.1076/snfe.31.3.179.13342

15. Lansac-Tôha FA, Velho LFM, Zimmermann-Callegari MC, Bonecker CC. On the occurrence of testate amoebae (Protozoa, Rhizopoda) in Brazilian inland Waters. I. Family Arcellidae. Acta Sci Biol Sci. 2000;22(22):355-363.

16. Torres VS, Schwarzbold A. Amebas testáceas ocorrentes na região de Porto Alegre, RS. III Novos registros de Testaceafilosea (Protoctista: Rhizopoda). Com Museu Cien Tecnol PUCRS. Série Zoologia. 2000;13(2):139-146.

17. Lansac-Tôha FA, Velho LFM, Takahashi EM, Aoyahui ASM, Bonecker CC. On the occurence of testate amoebae (Protozoa, Rhizopoda) in Brazilian inland water. V. Families Hyalospheniidae, Plagiopyxidae, Microcoryciidae, Cryptodifflugiidae, Phryganelidae, Euglyphidae, Trinematiidae and Cyphoderiidae. Acta Sci Biol Sci. 2001;23(2):333-347.

18. Lansac-Tôha FA, Velho LFM, Zimmermann-Callegari MC, Bonecker CC, Takahashi EM. On the occurrence of testate amoebae (Protozoa, Amoebozoa, Rhizopoda) in Brazilian inland waters. III. Family Difflugiidae: Genus Difflugia. Acta Sci Biol Sci. 2001;23(2):305-321.

19. Fulone LJ, Lima AF, Alves GM, Velho LFM, Lansac-Tôha FA. Composição de amebas testáceas (Protozoa-Rhizopoda) de dois córregos do Estado de São Paulo, incluindo novos registros para o Brasil. Acta Sci Biol Sci. 2005;27(2):113-118.

20. Leipnitz II, Silva JLL, Leão CJ, Ferreira F, Hansem MAF. Amebas testáceas (Protozoa, Rhizopoda) de ambientes límnicos do Parque Nacional da Lagoa do Peixe, RS, Brasil. GAEA. 2006;2(2):47-58. 
21. Bini LM, Vieira LCG, Machado J, Velho LFM. Concordance of Species Composition Patterns among Microcrustaceans, Rotifers and Testate Amoebae in a Shallow Pond. Internat Rev Hydrobiol. 2007;92 (1):9-22, doi: 10.1002/iroh.200610865

22. Lansac-Tôha FA, Zimmermann-Callegari MC, Alves GM, Velho LFM, Fulone LJ. Species richness and geographic distribuition of testate amoebae (Rhizopoda) in Brazilian freshwater environments. Acta Sci Biol Sci. 2007;29(2):185-195.

23. Alves GM, Velho LFM, Simões NR, Lansac-Tôha FA. Biodiversity of testate amoebae (Arcellinida and Euglyphida) in diferent habitats of a lake in the Upper Paraná River floodplain. Eur J Protistol. 2010;46:310-318, doi: 10.1016/j.ejop.2010.07.001

24. Regali-Seleghim MH, Godinho MJL, Matsumura-Tundisi T. Checklist dos "protozoários” de água doce do Estado de São Paulo, Brasil. Biota Neotrop. 2011;11(1):389-426, doi: 10.1590/S167606032011000500014

25. Silva MLC, Rangel ER, Lansac-Tôha FA, Schwind LTF, Joko CY. An annotated checklist of the Arcella (Arcellidae) from litoral zone of Paranoá lake-Brazil, with a pictorial key. Acta Sci Biol Sci. 2016;38(2):229-240, doi: 10.4025/actascibiolsci.v38i2.29187

26. Arrieira, RL, Schwind LTF, Alves GM, Lansac-Tôha FA. Estudos da biodiversidade de amebas testáceas para estratégias voltadas à preservação: uma revisão. Rev Agro Amb. 2017;10(2):567-586, doi: 10.17765/2176-9168.2017v10n2p567-586

27. Rosa FR, Orissaka TNF, Lopes IR, Silva WM. Checklist de tecamebas (Testacea) do estado de Mato Grosso do Sul, Brasil. Iheringia Sér Zool. 2017;107(supl.):e2017101, doi: 10.1590/1678-4766e2017101

28. Cunha AM. Contribuição para o conhecimento da fauna de protozoários do Brasil. Mem Inst Oswaldo Cruz. 1916;8:66-73.

29. Neumann-Leitão S, Nogueira-Paranhos JD. Zooplâncton do rio São Francisco - Região Nordeste do Brasil. Trab Oceanograf. 1987;20:173-196, doi: 10.5914/tropocean.v20i1.2631

30. Silva MB, Ribeiro SMMS, Velho, LFM. Composição de amebas testáceas (Amoebozoa: Rhizopoda) associadas à rizosfera de Eichhornia crassipes (Martius) Solomons (Pontederiaceae) no Rio Cachoeira, Bahia, Brasil: novos registros para o Nordeste. Acta Sci Biol Sci. 2009;9(4):192-203.

31. Cruz CF. Amebas testáceas: ocorrência e distribuição Baía de Iguape/BTS - Bahia, Brasil. Biotemas. 2012;25(3):1-10, doi: 10.5007/2175-7925.2012v25n3p1

32. Araújo AP, Nogueira EMS. Zooplâncton como bioindicador das águas do reservatório natural do povoado Olhos D’água do Souza, Glória, Bahia, Brasil. Rev Ouricuri. 2016;6(2):1-16.

33. Paina K, Melão M. Zooplankton community structure from tropical temporary ponds during a flood period. Limnetica. 2019;38:189-211.

34. Crispim MC, Freitas GTDP. Seazonal effects on zooplanktonic Community in a temporary lagoon of northest Brazil. Acta Limnol Bras. 2005;14(4):385-393.

35. Moreira RA, Rocha O, Santos RM, Dias ES, Moreira FWA, Eskinazi-Sant'anna EM. Composition, body-size structure and biomass of zooplankton in a high-elevation temporary pond (Minas Gerais, Brazil). Oecol Australis. 2016;20:81-93.

36. Bicudo DC. Considerações sobre metodologias de contagem de algas do perifíton. Acta Limnol Bras. 1990;3:459-475.

37. Scharzbold A. Métodos Ecológicos aplicados ao estudo do perifíton. Acta Limnol Bras. 1990;3:345392.

38. Torres VS, Jebram DHA. Arcella gibbosa microssoma var. n. (Protozoa, Sarcodina, Arcellinida): Descrição e observação feitas em seu cultivo. Biotemas. 1993;7(1):20-29.

39. Hardoim EL. Taxonomia e ecologia de Testacea (Protozoa: Rhizopoda) do Pantanal de Poconé - Rio Bento Gomes e Vazante Birici, Mato Grosso, Brasil. [tese]. São Carlos (SP): Universidade Federal de São Carlos; 1997. 341 p.

40. CONAMA. Resolução 357 de 17 de março de 2005, Brasília: Diário Oficial da União da República Federativa do Brasil, 18 de março seção 1, p. 58-63.

41. Bottrell HH, Duncan A, Gliwicz ZM, Grygierek E, Herzig A, Hillbricht-Ilkowska A, Kurasawa H, Larsson P, Weglenska T. A review of some problems in zooplankton production studies. Norw J Zool. 1976;24:419-456.

42. Velho LFM, Lansac-Tôha FA, Bini LM. Spatial and temporal variation in densities of testate amoebae in the plankton of the Upper Paraná River floodplain, Brasil. Hydrobiol. 1999;411:103-113, doi: 10.1023/A:1003889331767

43. Velho LFM, Bini LM, Lansac-Tôha FA. Testate amoeba (Rhizopoda) diversity in plankton of the Upper Paraná River floodplain, Brazil. Hydrobiol. 2004;523:103-111, doi: 10.1023/B:HYDR.0000033098.46753.9f

44. Deflandre G. Le genre Euglypha Dujardin. Arch für Protist. 1928;106:51-100. 
45. Deflandre G. Le genre Centropyxis Stein. Arch für Protist. 1929;67:322-375.

46. Gauthier-lièvre 1, ThomasR. Le genres Difflugia, Pentagonia, Maghrebia et Hoogenraadia (Rhizopodes Testacès) en Afrique. Arch für Protist. 1958;103:1-370.

47. Gauthier-Lièvre L, Thomas R. Le genres Cucurbitella Pènard. Arch für Protist. 1960;104(4):569-60.

48. Decloitre L. Le genre Arcella Ehrenberg. Arch für Protist. 1962;64:152-287.

49. Vucetich MC. Estudio de tecamebianos argentinos, en especial los del domínio pampasico. Rev del Museu de La Plata, ser Zool. 1973 11(108):287-332

50. Dioni W. Taxocenos de tecamebianos en cuencas isleñas del Parana medio. I. Los tecamebianos de la vegetacion flotante en el madrejon Don Felipe. Acta Zool Lilloana. 1974;27:200-239.

51. Ogden CG, Hedley RH. An atlas of freshwater testate amoebae. Oxford: Oxford University Press; 1980. $222 \mathrm{p}$.

52. Ogden CG, Zivkovic A. Morphological studies on some Difflugiidae from Yugoslavia (Rhizopoda, Protozoa). Bull Brit Museum Nat Hist Ser Zool. 1983;44(6):341-375.

53. Ogden CG. Observations on the systematics of the genus Difflugia in Britains (Rhizopoda, Protozoa). Bull Brit Museum Nat Hist Ser Zool. 1983;44:1-73.

54. Ogden CG. Notes on testate amoebae (Protozoa: Rhizopoda) from lake Vlasina, Yugoslavia. Bull Brit Museum Nat Hist Ser Zool. 1984;47(5):241-263.

55. Torres VS. Amebas testáceas (Protista: Rhizopoda) associadas à rizosfera de Eichhornia crassipes (Martius) Solomons na represa Lomba do Sabão, Porto Alegra, RS. [dissertação]. Pontifícia: Universidade Católica do Rio Grande do Sul; 1996

56. Torres VS. Estudos sobre Difflugia lobostoma Leidy (Protista, Rhizopoda, Testacealobosea). Rev Bras Zool. 1996;13(2):475-487.

57. Hardoim EL, Heckman CW. The seasonal sucession of biotic communities in wetlands of the tropical wet and dry climatic zone: IV. Free living sarcodineos and ciliates if the Pantanal of Mato Grosso, Brazil. Int Rev Hydrobiol. 1996;81(3):367-384, doi: 10.1002/iroh.19960810307

58. Dabés MBGS, Velho LFM. Assemblage of testate amoebae (Protozoa, Rhizopoda) associated to aquatic macrophytes stands in a marginal lake of the São Francisco river floodplain, Brazil. Acta Sci Biol Sci. 2001;23(2):299-304.

59. Snegovaya N, Alekperov I. Fauna of testate amoebae of western Azerbaijan rivers. Protistol. 2005;4(2): 149-183.

60. Tsyganov A, Mazel Y. Morphology and biometry of Arcella intermedia (Deflandre, 1928) comb. nov. from Russia and a review of hemispheric species of the genus Arcella (Testacealobosea, Arcellinida). Protistol. 2007;4(4):361-369.

61. Alves GM. Amebas testáceas (Arcellinida e Euglyphida) de diferentes biótipos de uma lagoa da planície de inundação do alto rio Paraná. [tese]. Maringá: Universidade Estadual de Maringá; 2010. 52 p.

62. Brito CDCA, Franco LD, Lopes MIT, Pessoa LL, Porfírio AF. Levantamento preliminar da comunidade protozooplanctônica de um trecho da Sub-Bacia do Rio Maranhuapinho, Maracanaú - CE. IBEAS. 2016

63. Legendre P, Legendre L. Numerical ecology. Developments in Environmental Modelling. Amsterdam: Elsevier; 1998. 853 p.

64. Valente JPS, Padilha PM, Silva AMM. Contribuição da cidade de Botucatu-SP com nutrientes (fósforo e magnésio) na eutrofização da represa de Barra Bonita. Eclética Quím. 1997;22:31-48, doi: 10.1590/S0100-46701997000100004

65. Nogueira PF, Cabral JBP, Oliveira, SF, Rocha IR. Eutrofização no reservatório da UHE Foz do Rio Claro (GO). Rev Depart Geogr. 2015;30:19-33, doi: 10.11606/rdg.v30i0.90090

66. Silva MA, Araújo RR. Análise temporal da qualidade da água no Córrego Limoeiro e no Rio Pirapozinho no Estado de São Paulo - Brasil. Rev Formação (Online). 2017;1(24):182-203, doi: 10.33081/formacao.v1i24.4656

67. Esteves FA. Fundamentos de Limnologia. Rio de Janeiro: Interciência - FINEP; 2011. 826 p.

68. Moraes AJ. Manual para avaliação da qualidade da água. São Carlos: Rima; 2001. 45 p.

69. Sena MGT, Lopes FB, Andrade EM, Oliveira CMB, Lima FJO. Variabilidade da condutividade elétrica e do pH nas águas superficiais da Região Semiárida. III INOVAGRI International Meeting; 2015. Fortaleza, Brasil.

70. Cunha AH, Tartler N, Santos RB, Fortuna JL. Análise microbiológica da água do Rio Itanhém em Teixeira de Freitas, BA. Rev Bioci. 2010;16(2):86-93.

71. Silva ABA, Ueno M. Qualidade sanitária das águas do Rio Una, São Paulo, Brasil, no período das chuvas. Rev Bioci. 2008;14(1):82-86.

72. Torres JLR, Silva SR, Pedro CAS, Passos AO, Gomes JQ. Morfometria e Qualidade da Água da Microbacia do Ribeirão da Vida em Uberaba - MG. GST. 2009;2(1):01-09. 
73. Duarte K, Gomes L, Dozzo, A, Rocha F, Lira S, Demarchi J. Qualidade microbiológica da água para consumo animal. Bol Ind Animal. 2014;71:135-142.

74. Velho LFM, Lansac-Tôha FA, Bini LM. On the occurrence of the testate amoebae (Protozoa, Rhizopoda) in Brazilian Inland waters. II. Families Centropyxidae, Trigonopyxidae and Plagiopyxidae. Acta Sci Biol Sci. 2001;22(2):365- 374.

75. Velho LFM, Lansac-Tôha FA, Bonecker CC, Zimmermann-Callegari MC, Aoyagui ASM. On the occurrence of testate amoebae (Protozoa, Rhizopoda) in Brazilian Inland Waters. IV. Families Difflugiidae (genera Cucurbitella, Lagenodifflugia, Pentagonia, Pontigulasia, Protocucurbitella, Suiadifflugia) and Lesquereusiidae (genera Lesquerensia, Quadrulella, Netzelia). Acta Sci Biol Sci. 2001;9(2):323-332.

76. Van Onsem S, De Backer S, Triest L. Microhabitat zooplankton relationship in extensive macrophyte vegetations of eutrophic clear-water ponds. Hydrobiol. 2010;656(1):67-81, doi: 10.1007/s10750-0100442-1

77. Petruceli MEA, Alvim TCO, Estanislau CAM. Estudo dos microinvertebrados aquáticos como bioindicadores de qualidade de água e desenvolvimento de índices saprobióticos. Rev Iniciação Cient. 2016;16:108-116.

78. Nibshibe Y, Manage PM, Kawabata Z, Nakano S. Trophic coupling of a testate amoeba and Microcystis species in a hypertrophic pond. Limnology. 2004;5:71-76.

79. Barbieri MS, Godinho-Orlandi MJL. Ecological studies on the planktonic protozoo of a eutrophic reservoir (Rio Grande Reservoir - Brazi1). Hydrobiologia. 1989;183:1-10.

80. Biyu SA. comparative study on planktonic ciliates in two shallow mesotrophic lakes (China): species composition, distribution and quantitative importance. Hydrobiologia. 2000;427:143-153.

81. Velho LM, Pereira DG, Pagioro TA, Santos VD, Perenha MCZ, Lansac-Tôha, FA. Abundance, biomass and size structure of planktonic ciliates in 93 reservoirs with distinct trophic states. Acta Limnol Bras. 2005;17(4):361-371.

82. Xu M, Cao H, Xie P, Deng D, Feng W, Xu J. The temporal and spatial distribution, composition and abundance of protozoa in Chaohu Lake, China: Relationship with eutrophication. Europ J Protistol. 2005;14:183-192.

83. Souza MBG. Guia das Tecamebas Bacia do Rio Peruaçu - Minas Gerais: Subsídios para a conservação

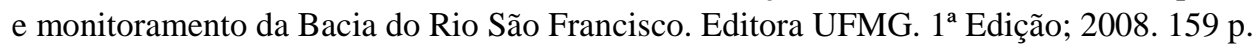

